\title{
myPersonalEWS: Uma Abordagem Colaborativa para Alertar Surdos, Cegos e Analfabetos sobre Desastres
}

\author{
Jaziel Souza Lobo ${ }^{1,2}$, Vaninha Vieira ${ }^{2}$ \\ ${ }^{1}$ Instituto Federal de Sergipe (IFS) - Campus São Cristóvão \\ ${ }^{2}$ Universidade Federal da Bahia (UFBA) - Salvador - BA \\ jaziel.lobo@ifs.edu.br, vaninha@ufba.br
}

\begin{abstract}
Floods, storms and landslides are some of the situations that can lead to natural disasters with loss of life and damage to society. In order to alert the population, early warning systems are used. Alert messages are usually disseminated in text format, excluding vulnerable populations who have difficulty or cannot read, such as the illiterate, blind and deaf people. This paper presents an approach to alert vulnerable groups through a Collaborative and ContextSensitive Early Warning System.
\end{abstract}

Resumo. Inundações, alagamentos, temporais e deslizamentos de terra são algumas das situações que podem levar a desastres naturais com perda de vidas e danos à sociedade. A fim de alertar a população, são utilizados sistemas de alerta antecipado. Geralmente as mensagens de alertas são disseminadas em formato de texto, o que acaba excluindo populações vulneráveis que têm dificuldade ou não saibam ler, a exemplo dos analfabetos, cegos e surdos. O presente trabalho apresenta uma abordagem para alertar grupos vulneráveis por meio de um Sistema de Alerta Antecipado Colaborativo e Sensível ao Contexto.

\section{Introdução}

Emergências como terremotos, erupções vulcânicas, inundações, deslizamentos de terra ou incêndios têm afetado a vida de muitas pessoas e gerado situações de desastres que ocorrem ao redor do mundo. Ao se prever um cenário de emergência, é imprescindível que a sociedade seja comunicada de forma rápida para a redução de vítimas e danos ambientais [Anhong et al. 2009]. Os sistemas que enviam alertas são chamados de Sistemas de Alerta Antecipado, ou EWS da sigla em inglês Early Warning Systems.

Segundo [Meissen et al. 2014], a maioria dos EWS existentes disseminam em massa os alertas via SMS, Cell-Broadcasting ou Serviços de Notificação Push. Na divulgação em massa, a mesma mensagem é enviada a todas pessoas e desconsidera totalmente que podem existir pessoas com deficiências ou analfabetos entre aqueles que recebam o alerta.

Dados da Organização Mundial da Saúde [WHO 2015] relatam que cerca de $15 \%$ da população mundial (mais de um bilhão de pessoas) possuem alguma forma de deficiência. No Brasil, este percentual é ainda maior, 23\% da população [IBGE 2014]. Populações vulneráveis como as pessoas com deficiências estão sujeitas a um risco especial em um desastre e é fundamental que as suas necessidades sejam consideradas na concepção de sistemas de preparação e aviso de desastres [Sullivan and Häkkinen 2011]. 
Avaliando-se 38 estudos sobre EWS, apenas oito deles abordavam algum suporte para pessoas com deficiência. A partir destes fatos, surge a inquietação para se pesquisar e propor uma abordagem para apoiar a comunicação de alertas para os grupos vulneráveis de pessoas surdas, cegas e analfabetas. A principal contribuição deste trabalho está na concepção colaborativa na geração dos recursos, pois abordagens automáticas podem gerar interpretações erradas, como no caso da tradução distorcida do inglês para o espanhol da palavra "warning"que gerou a perda de 29 vidas [Phillips and Morrow 2007]. Em relação à tradução automática do Português Brasileiro para a Língua Brasileira de Sinais (LIBRAS), o estudo de [Corrêa et al. 2018] revela uma baixa produção científica sobre o tema, inclusive, segundo o autor, os artigos analisados não explicitam as tecnologias de tradução utilizada. Desta forma, tratamentos automáticos aumentam a complexidade nos órgãos de alerta, pois há a necessidade de que existam especialistas com conhecimento dos diversos domínios para avaliar se o resultado da tradução está correto. O presente trabalho apresenta uma abordagem para apoiar EWS no envio de alertas para grupos vulneráveis de pessoas surdas, cegas e analfabetas através da colaboração entre o centro de comando, intérpretes de libras e narradores voluntários.

\section{Trabalhos Relacionados}

Atualmente os EWS fazem um cadastro prévio de pessoas, cujos dados são utilizados para personalizar os alertas que serão enviados [Klafft and Ziegler 2014]. Apesar do cadastro, a maioria dos EWS fazem distribuições em massa de alerta para todos usuários dentro da área afetada [Meissen et al. 2014]. Um exemplo é o sistema IDAP, utilizado para alertar a população do Brasil [Brasil. Ministério da Integração Nacional 2018], que envia de forma massiva mensagens SMS para todos os usuários cadastrados que estejam na área de risco.

Em [Klafft and Ziegler 2014] os autores apresentam a possibilidade de enviar alertas adaptados para idosos, pessoas com deficiência, famílias com crianças, ou turistas a partir de uma base centralizada de mensagens de alerta de autoridades locais, regionais ou nacionais. Em [Malizia et al. 2009], os autores apresentam CAP-ONES, um sistema baseado em ontologia para gerar notificações de alerta de emergência adaptadas para diferentes tipos de usuários, mídias e dispositivos. Os usuários devem informar o perfil e possíveis mídias para receber os alertas. A ontologia também propõe mídias específicas para cada deficiência. O sistema cruza estas informações e envia o alerta com a mídia recomendada ou definida pelo usuário. Embora os autores dos dois trabalhos abordem a questão do envio de alerta personalizado, nenhum processo é previsto para a geração destas adaptações, ficando a cargo de cada autoridade gerar os recursos.

Em [Rahman et al. 2012] os autores têm o objetivo de alertar situações de desastre a pessoas em área de risco e possibilitar que as autoridades de controle de evacuação regional possam realizar o rastreamento destas vítimas. Ainda segundo esse trabalho, além do público geral, a proposta também atende a usuários cegos uma vez que o sistema envia um alerta vibratório e um de áudio ao mesmo tempo para aqueles usuários que estão na área de risco. Apesar disto, a única informação contextual utilizada pelo sistema é a localização dos usuários, não sendo obtidas informações sobre deficiências dos usuários, o que impossibilita dar tratamento diferenciado a outros grupos, como por exemplo, usuários surdos.

No estudo [Costa et al. 2017], apesar de não ser um EWS, os autores apresen- 
tam uma abordagem que tem uma relação com a proposta deste trabalho. O objetivo dos autores é apoiar a comunicação de pessoas surdas por meio de ferramentas computacionais móveis e colaborativas. Nessa proposta foi desenvolvido um aplicativo onde são incluídas palavras na língua portuguesa textual e recursos em libras com significados para estas palavras. Segundo o trabalho, a pesquisa é exploratória para permitir a construção de hipóteses ou proposições para os autores. O problema que se identifica nesta proposta é que palavras isoladas podem ter significados diferentes que irão depender do contexto onde ela é aplicada, o que inviabilizaria, por exemplo, utilizar o dicionário desse aplicativo para compor mensagens de alerta em um EWS.

\section{Estratégia Experimental}

De acordo com a revisão da literatura, pessoas surdas possuem dificuldades de leitura e escrita e dispõe de baixo nível de letramento [Bisol et al. 2010]. Com base nesta constatação, uma proposição inicial fora feita com uma abordagem de alertas baseado em textos adaptados para cegos e surdos, como pode ser visto em mais detalhes em [Lobo and Vieira 2017]. Visando atender ao objetivo desta proposta, três estudos empíricos foram definidos para atender ao objetivo da proposta: (i) entrevista com especialistas, (ii) survey com público alvo e (iii) um estudo experimental para avaliar o modelo.

\subsection{Entrevista com Especialistas}

Uma vez que o estudo é voltado para EWS com foco em grupos vulneráveis, definiram-se dois grupos de especialistas de domínio para serem entrevistados: Especialistas da área de crise e emergência e Especialistas de Grupos Vulneráveis. Como representantes do primeiro grupo, foram entrevistados especialistas do Departamento Estadual de Proteção e Defesa Civil - DEPEC, que é o órgão responsável pela operacionalização o sistema IDAP no estado de Sergipe. De acordo com os entrevistados, não existe um produto específico para o público de deficientes, embora qualquer estudo, ideia ou solução que venha a surgir para esse público eles têm interesse e estão dispostos a colaborar.

A segunda etapa de entrevistas foi realizada com os especialistas dos grupos vulneráveis. Foram entrevistados quatro intérpretes de LIBRAS, como especialistas no domínio de pessoas surdas, e uma pessoa que trabalha no domínio de pessoas cegas. Com a realização das entrevistas, foi possível ratificar a constatação sobre a dificuldade com leitura e escrita de pessoas surdas, mas quando questionados sobre como deveria ser uma mensagem de alerta para uma pessoa surda, por unanimidade os intérpretes afirmaram que deveria ser uma mensagem em LIBRAS. E questionando-se sobre a abordagem de texto, os intérpretes informaram que o texto deveria ser muito curto e direto. Um dos intérpretes explicou que se o texto da mensagem fosse muito longo, o surdo só tomaria alguma atitude depois que ele entendesse todo o conteúdo e que se fosse uma mensagem sobre um alto risco, ele poderia morrer tentando entender o texto. Outro ponto abordado foi sobre como chamar a atenção de uma pessoa surda para olhar o celular quando ele receber um alerta. Os entrevistados relataram que luzes piscando e a vibração do celular seriam as melhores formas de chamar a atenção. Um dos intérpretes relatou que poderiam ser luzes piscando com cores variadas.

Com relação às pessoas cegas, o especialista do domínio relatou que muitos dispositivos possuem leitores de tela e fazem a transcrição do texto para voz e quando ques- 
tionados sobre como chamar a atenção de uma pessoa cega para o celular foi relatado que seria interessante avisar antes que uma mensagem de alerta irá chegar para que a pessoa fique atenta ao alerta que irá receber. Como resultado das entrevistas, concebeu-se a primeira versão do modelo de contexto e uma arquitetura conceitual da proposta.

\subsection{Survey com Público Alvo}

De forma preliminar realizou-se um estudo exploratório através de entrevistas semiestruturadas com pessoas cegas e surdas com o objetivo de conhecer como realizar entrevistas com este público. A proposta de aplicação do survey com os sujeitos alvo da proposta deverá ser realizada através de um questionário com perguntas estruturadas com o objetivo de conhecer as necessidades e preferências dos usuários no tocante a como chamar a sua atenção quando um novo alerta for entregue a ele e quais as personalizações necessárias na exibição do alerta. Como fruto deste survey pretende-se atualizar o modelo de contexto, obtendo uma segunda versão com regras comportamentais mais direcionadas.

\subsection{Experimento Controlado}

A versão final do modelo de contexto e da proposta de um EWS com foco no usuário deverá possibilitar que um EWS possa enviar alertas de acordo com a necessidade do usuário, tanto em relação ao formato de mídia de preferência, quanto em forma de apresentação desta mídia. Diante disto, propõe-se como experimentação final, um experimento controlado com simulações onde os sujeitos do estudo recebam alertas em formato texto, como atualmente é enviado por muitos sistemas de alerta, a exemplo do que é praticado hoje pelo IDAP, e também recebam mensagens personalizadas de acordo com o modelo proposto. O resultado deste trabalho servirá também para aperfeiçoar o modelo, caso alguma distorção seja identificada.

\section{Solução Proposta: myPersonalEWS}

Os dados sobre o risco e recomendações do alerta são recebidos no EWS em arquivos no formato CAP - Common Alerting Protocol. O CAP é um padrão mundialmente usado e bem referenciado pela comunidade científica [Barros et al. 2015] que contém vários elementos contextuais sobre emergências. O CAP é um padrão aberto, não proprietário e baseado em XML [OASIS 2010]. De uma forma geral, um EWS quando recebe uma mensagem no formato CAP, deve disseminar alertas sobre o perigo eminente para as pessoas que estão em área de risco após autorização de algum membro das forças operacionais.

A arquitetura conceitual base desta proposta para um EWS sensível ao contexto foi discutida no estudo [Rodrigues et al. 2017]. No estudo a arquitetura possui três componentes: Gerenciador de Contexto (GC) que recebe as informações do perigo (mensagem CAP), do usuário e do dispositivo receptor; o Construtor de Mensagem (CM) que tem a responsabilidade de adaptar o conteúdo das mensagens para cada indivíduo, através da identificação de quem deve receber as mensagens (pessoas em área de risco) e qual a estratégia de disseminação em diferentes canais de acordo com os diferentes formatos de mídia que existam na mensagem (texto, imagem, áudio, vídeo); e o Disseminador que envia as mensagens de alerta aos receptores através de cada canal de comunicação selecionado usando o formato de dados escolhido (e disponível) para o conteúdo de uma mensagem. Neste trabalho propõe-se a inclusão de um novo componente, o TRADUTOR DE MENSAGEM (TM). 
Ao se analisar mensagens CAP do Instituto Nacional de Meteorologia - INMET, percebeu-se que o vocabulário utilizado é reduzido ao domínio de crise e emergências e que existe um padrão na disseminação das mensagens. Assim sendo, o componente TM será responsável pela decomposição das mensagens e geração de recursos personalizados para cada grupo vulnerável. Tomando como exemplo a adaptação para pessoas surdas, seriam gerados recursos em LIBRAS e para analfabetos e pessoas cegas, recursos em áudio. Para a geração dos recursos, a proposta é que exista uma colaboração entre autores e validadores de recursos. Um autor seria qualquer pessoa da sociedade que tenha a expertise necessária, por exemplo um intérprete de libras ou um locutor/narrador voluntário. Já o validador é uma pessoa com notório saber no domínio específico, um professor de LIBRAS por exemplo, que possa atestar que o recurso gerado está em conformidade com a mensagem original. O modelo para gerar colaborativamente os recursos através do módulo TM pode ser visto na Figura 1.

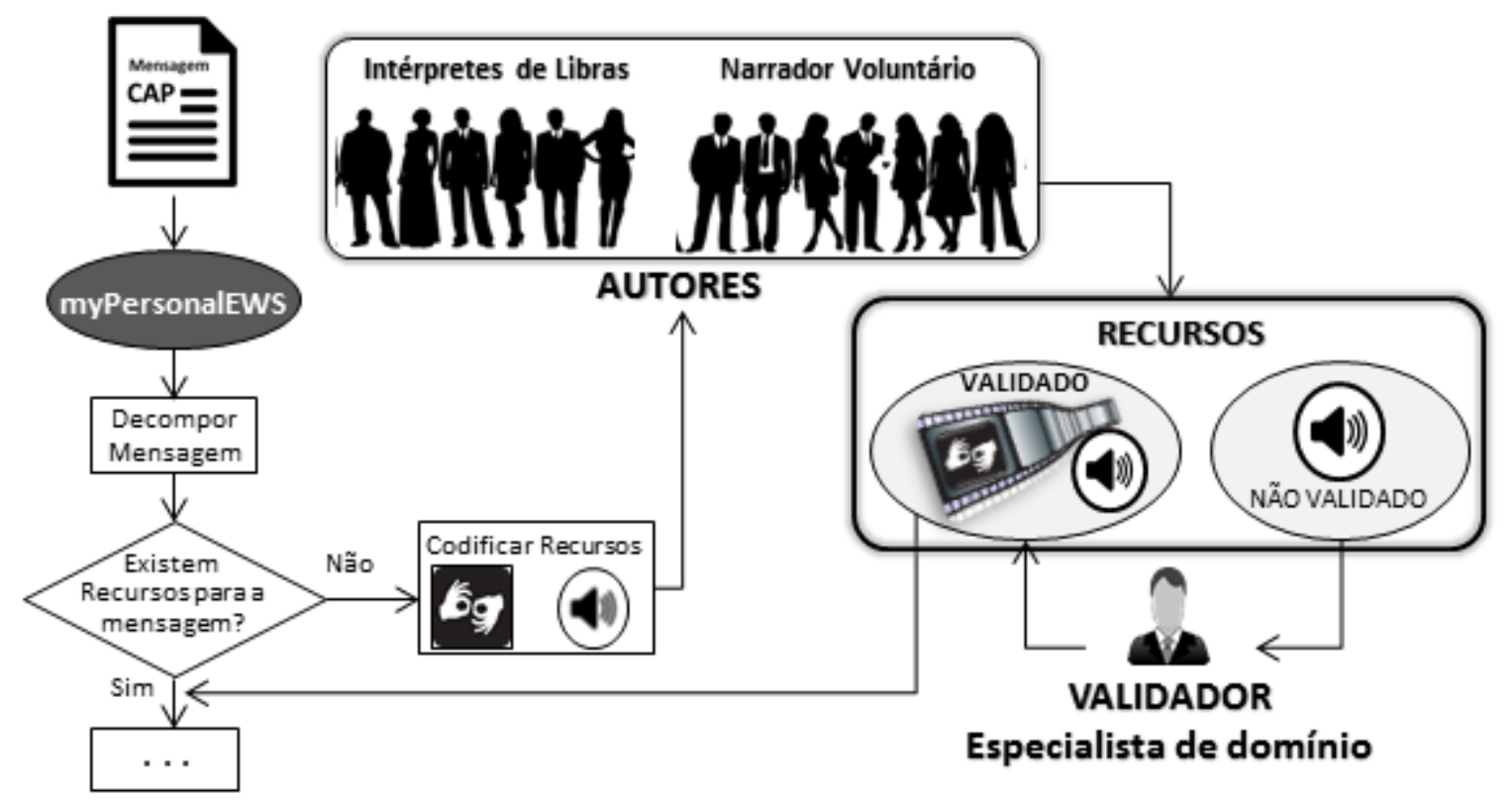

Figura 1. Modelo Comportamental para gerar recursos.

\section{Conclusões e Trabalhos Futuros}

Este trabalho apresentou uma proposta para um EWS para surdos, cegos e analfabetos através de abordagem Colaborativa e Sensível ao Contexto. A proposta deste trabalho é que exista uma colaboração entre os órgãos disseminadores e órgãos com expertise no domínio da adaptação necessária. As próximas etapas são: a aplicação do survey com pessoas do Público Alvo e a realização de um experimento controlado. Com vistas a validação da proposta, o survey e experimento controlado serão realizados com o grupo de pessoas surdas. A opção se dá porque além dos surdos possuírem baixo nível de letramento com dificuldades relativas à leitura e escrita, existe a limitação da sociedade em se comunicar com eles, tornando-os mais vulneráveis. Para o experimental controlado propõe-se simulações com alertas em formato texto, e seguindo as regras do modelo de contexto desenvolvido. 


\section{Referências}

Anhong, L., Xiang, L., Wenjuan, F., Ning, A., Jian, Z., Lian, L., and Yongzhong, S. (2009). Blue arrow: A web-based spatially-enabled decision support system for emergency evacuation planning. 2009 Int. Conf. Bus. Intell. Financ. Eng. BIFE 2009.

Barros, R., Kislansky, P., Salvador, L., Almeida, R., Breyer, M., and Gasparin, L. (2015). Edxl-rescuer ontology: Conceptual model for semantic integration. In ISCRAM.

Bisol, C. A., Valentini, C. B., Simioni, J. L., and Zanchin, J. (2010). Deaf Students in higher education: Reflections on inclusion. Cadernos de Pesquisa, 40:147 - 172.

Brasil. Ministério da Integração Nacional (2018). Portaria nº 413, de 13/09/2018.

Corrêa, Y., Giotti, J., Cruz, C. R., and Ribeiro, V. G. (2018). Produção científica brasileira sobre tradução automática português brasileiro-libras: uma revisão sistemática de literatura. Revista virtual de estudos da linguagem. Novo Hamburgo, RS. p. 179-203.

Costa, S. E. d., Berkenbrock, C. D. M., Sell, F. S. F., and Berkenbrock, G. R. (2017). iLibras como facilitador na comunicação efetiva do surdo: uma ferramenta colaborativa móvel. In XIV Simpósio Bras. Sist. Colab. - SBSC, pages 1269-1283, São Paulo.

IBGE (2014). Perfil dos Municípios Brasileiros 2013, volume 1. Rio de Janeiro.

Klafft, M. and Ziegler, H. G. (2014). A concept and prototype for the integration of multi-channel disaster alert systems. pages 20:1-20:4.

Lobo, J. S. and Vieira, V. (2017). Sistema de alerta antecipado sensível ao contexto:uma abordagem baseada em textos para cegos e surdos. In Anais do X Workshop de Teses e Dissertações em Sistemas de Informação WTDSI 2017, SBSI 2017, pages 60-63.

Malizia, A., Acuna, P., Onorati, T., Diaz, P., and Aedo, I. (2009). CAP-ONES: an emergency notification system for all. International Journal of Emergency Management.

Meissen, U., Hardt, M., and Voisard, A. (2014). Towards a general system design for community-centered crisis and emergency warning systems. ISCRAM 2014 - 11th International Conference on Information Systems for Crisis Response and Management.

OASIS (2010). Common alerting protocol version 1.2. https://goo.gl/g1OJJG. Accessed in 21-05-2016.

Phillips, B. D. and Morrow, B. H. (2007). Social Science Research Needs: Focus on Vulnerable Populations, Forecasting, and Warnings. Natural Hazards Review.

Rahman, K. M., Alam, T., and Chowdhury, M. (2012). Location based early disaster warning and evacuation system on mobile phones using openstreetmap. In 2012 IEEE Conference on Open Systems, pages 1-6.

Rodrigues, T., Machado, F. A. L., Lobo, J. S., Vieira, V., and Neto, M. C. M. (2017). Towards a context-sensitive system to support crisis communication message dissemination. In SBSI 2017, pages 166-173, Universidade Federal de Lavras-UFLA.

Sullivan, H. T. and Häkkinen, M. T. (2011). Preparedness and warning systems for populations with special needs: Ensuring everyone gets the message (and knows what to do). Geotechnical and Geological Engineering, 29(3):225-236.

WHO (2015). WHO global disability action plan 2014-2021. Better health for all people with disability. 